\title{
Widowed status predicts poor overall survival of Chinese patients with prostate cancer
}

\author{
Si-Huai Huang, Yi-Ning Li, Jian-Wei Li, Yi-Hong Guo, Xue-Feng Su \\ Departments of Urology, the Second Affiliated Hospital of Fujian Medical University, Quanzhou 362000, China \\ Contributions: (I) Conception and design: SH Huang, YN Li; (II) Administrative support: SH Huang, XF Su; (III) Provision of study materials or \\ patients: SH Huang, XF Su; (IV) Collection and assembly of data: JW Li, YH Guo; (V) Data analysis and interpretation: SH Huang, XF Su; (VI) \\ Manuscript writing: All authors; (VII) Final approval of manuscript: All authors. \\ Correspondence to: Dr. Xue-Feng Su. Department of Urology, the Second Affiliated Hospital of Fujian Medical University, 34 Zhongshan North Road, \\ Quanzhou 362000, China. Email: 77120563@fjmu.edu.cn.
}

Background: Little is known about the influence of marital status on Chinese prostate cancer (PCa) patients. Marital status may have an impact on overall survival in Chinese men with prostate cancer.

Methods: We identified 4,208 Chinese patients diagnosed with PCa between 2004 and 2015 in the Surveillance, Epidemiology, and End Results (SEER) database. Univariate and multivariate Cox proportional hazard models were used to determine the impact of marital status on the overall survival (OS) of Chinese PCa patients. Survival analysis was performed using the Kaplan-Meier method. Smoothing function and threshold effect analysis were performed to determine the turning points of variables.

Results: Univariate analysis demonstrated that marital status, prostate-specific antigen (PSA) category, surgery status, $\mathrm{T}$ stage, $\mathrm{N}$ stage, and M stage were associated with OS. Multivariate analysis further indicated that marital status, PSA category, surgery status, T stage, and M stage were independent risk factors of OS. Survival analysis demonstrated that the nonwidowed group had a better OS than the widowed group. The risk of poor OS increased rapidly with the PSA level up to the turning point 15.6 and $45.4 \mathrm{ng} / \mathrm{mL}$ in the nonwidowed group (HR =1.089; 95\% CI: 1.064-1.115; $\mathrm{P}<0.0001)$ and the widowed group (HR =1.056; 95\% CI: $1.028-1.084 ; \mathrm{P}<0.001)$, respectively.

Conclusions: In conclusion, this study demonstrated that widowed status greatly affects the OS of Chinese PCa patients. Altogether, this study highlights the importance of psychological intervention, especially for widowed Chinese PCa patients. Timely psychological intervention for widowed Chinese PCa patients might improve the survival outcomes of PCa.

Keywords: Marital status; widowhood; overall survival (OS); prostate cancer (PCa)

Submitted Jul 27, 2019. Accepted for publication Nov 11, 2019.

doi: $10.21037 /$ tcr.2019.11.48

View this article at: http://dx.doi.org/10.21037/tcr.2019.11.48

\section{Introduction}

Prostate cancer $(\mathrm{PCa})$ is the most frequently diagnosed cancer and the third leading cause of death for men in the United States $(1,2)$. In China, the incidence of PCa has increased rapidly and unexpectedly for the past twenty years (3-6). Nowadays, the mechanism of PCa remains poorly understood. Urologists endeavor to identify risk factors associated with PCa since the identification and characterization of risk factors might provide further insight into the treatment and prevention of $\mathrm{PCa}(7)$.

Nowadays, increased studies have assessed the influence of marital status on overall survival among patients with varieties of malignancy. However, whether marital status plays an important role in overall patient survival is still contentious. Adhering to the vow, "Til death do us part", might be associated with better survival benefits. Some studies (8-12) indicated that patients' marital status was a 
risk factor in their survival outcome. Other investigations (12-14) reported that there was no significant association between marital status and survival.

It is reported that marriage might have a strong effect on various physiological behaviors $(15,16)$. Married patients with malignancy might derive tangible clinical benefits. Only two studies have demonstrated the survival benefits of marital status in prostate cancer patients. However, to the best of our knowledge, no study reported the impact of marital status on survival among Chinese PCa patients. In this study, we used the Surveillance, Epidemiology, and End Results (SEER) database to study the influence of marital status on survival among Chinese PCa patients.

\section{Method}

\section{Patient population and study design}

The SEER database is maintained by the National Cancer Institute and reserves demographics, incidence and survival outcomes of patients (17). We used the SEER database to identify 4,208 Chinese patients diagnosed in 2004 through 2015 with PCa. Patients with insufficient marital status information were excluded from this study. The following demographic variables of each Chinese patient were collected: marital status (single, married, divorced/ separated, widowed), age, and diagnosed years. The clinicopathological variables included grade, $\mathrm{T}$ stage, $\mathrm{N}$ stage, $M$ stage, and prostate-specific antigen (PSA). The treatment variables included surgery status and survival time. The primary survival outcome was overall survival (OS), calculated as the date of the initial diagnosis to the date of death due to all kinds of reasons.

\section{Statistical analysis}

All statistical analyses were performed using the $\mathrm{R}$ software (version 3.4.3). Patient characteristics were compared with the t-test or chi-squared test. Five-year survival rates were estimated by using the Kaplan-Meier method. The effect of marital status on the overall survival of PCa in Chinese patients was estimated. Age, PSA level, marital status, and surgery were adjusted for the Cox model. Subgroup analysis was performed to determine the potential confounding factors associated with marital status. Ninety-five percent confidence intervals were calculated for each hazard ratio. A two-piecewise linear regression model was applied to examine the threshold effect of the PSA level on OS between the widowed group and the nonwidowed group by using a smoothing function. The threshold level was identified along a pre-defined interval, and the turning point that gave the maximum model likelihood was selected (18). $\mathrm{P}<0.05$ was considered statistically significant.

\section{Results}

\section{Patient characteristics}

A total of 4,208 eligible Chinese patients with PCa from the SEER database were identified in this study. Among them, 3,641 (86.526\%) were married, 277 (6.583\%) were single, 140 (3.327\%) were divorced, and $150(3.565 \%)$ were widowed. The median follow-up time was 70, 61, 59, and 67 months in married, single, divorced, and widowed groups, respectively. The widowed group had the highest proportion of elderly patients $(\geq 70$ years $)(\mathrm{P}<0.001)$, more patients with PSA higher than $20 \mathrm{ng} / \mathrm{mL}(\mathrm{P}<0.004)$, the lowest proportion receiving surgery $(\mathrm{P}<0.001)$, and the highest proportion of metastasis $(\mathrm{P}<0.001)$. The characteristics of Chinese patients with $\mathrm{PCa}$ were listed in Table 1.

Widows had poorer OS than patients who were nonwidowed. The 5-year OS in married, single, divorced, and widowed patients were $91.14 \%, 86.73 \%, 83.90 \%$, and $76.89 \%$, respectively (log-rank test, $\mathrm{P}<0.001)$. Univariate analysis demonstrated that marital status, PSA category, surgery status, $\mathrm{T}$ stage, $\mathrm{N}$ stage, and $\mathrm{M}$ stage were associated with OS. Multivariate analysis further indicated that marital status, PSA category, surgery status, T stage, and $M$ stage were independent risk factors of OS. The widowed group had approximately 2 -fold higher risk of poor OS than that of the married group ( $\mathrm{HR}=2.006 ; 95 \%$ CI: 1.477-2.724; $\mathrm{P}<0.001)$. In terms of single and divorced groups, the survival outcomes were comparable to the married group (Table 2).

Married, single, and divorced groups were then combined as the nonwidowed group because of the comparable OS among these three groups. Subgroup analysis was then performed in terms of the widowed group and the nonwidowed group in Chinese patients to determine the confounding factors between these two groups. The characteristics of widowed patients and nonwidowed patients are demonstrated in Table 3. Survival analysis demonstrated that the nonwidowed group had a better OS than those in the widowed group (Figure 1).

The results of the subgroup analysis demonstrated that 
Table 1 The characteristics of Chinese patients with prostate cancer in different marital status

\begin{tabular}{|c|c|c|c|c|}
\hline Marital status & Married, $N=3,641$ & Single, N=277 & Divorced, $N=140$ & Widowed, $N=150$ \\
\hline$<70$ & 1,967 (54.024) & $172(62.094)$ & $90(64.286)$ & $21(14.000)$ \\
\hline$\geq 70$ & $1,674(45.976)$ & $105(37.906)$ & $50(35.714)$ & $129(86.000)$ \\
\hline \multicolumn{5}{|l|}{ Year } \\
\hline 2010-2015 & $1,523(41.829)$ & $132(47.653)$ & $70(50.000)$ & $58(38.667)$ \\
\hline \multicolumn{5}{|l|}{ PSA category } \\
\hline$<4$ & $232(6.372)$ & $18(6.498)$ & $13(9.286)$ & $10(6.667)$ \\
\hline$\geq 4,<10$ & 2,170 (59.599) & 155 (55.957) & $83(59.286)$ & $68(45.333)$ \\
\hline \multicolumn{5}{|l|}{ Surgery } \\
\hline No & $2,188(60.093)$ & $170(61.372)$ & $95(67.857)$ & 113 (75.333) \\
\hline Yes & $1,453(39.907)$ & 107 (38.628) & $45(32.143)$ & $37(24.667)$ \\
\hline \multicolumn{5}{|l|}{$\mathrm{T}$} \\
\hline $\mathrm{T} 1$ & $1,557(42.763)$ & $127(45.848)$ & $67(47.857)$ & $67(44.667)$ \\
\hline $\mathrm{T} 2$ & $1,666(45.757)$ & $113(40.794)$ & $50(35.714)$ & $68(45.333)$ \\
\hline T3 & 357 (9.805) & $27(9.747)$ & $18(12.857)$ & $13(8.667)$ \\
\hline $\mathrm{T} 4$ & $61(1.675)$ & $10(3.610)$ & $5(3.571)$ & $2(1.333)$ \\
\hline \multicolumn{5}{|l|}{ M } \\
\hline M1 & $106(2.911)$ & $17(6.137)$ & $5(3.571)$ & $12(8.000)$ \\
\hline
\end{tabular}

the receipt of surgery was associated with a better OS in the nonwidowed group. However, surgery status was not associated with OS in the widowed group. Lymph node metastasis was not associated with OS in the nonwidowed group and in the widowed groups. However, T4 stage, PSA levels higher than $20 \mathrm{ng} / \mathrm{mL}$, and distant metastasis were associated with poor OS in the nonwidowed group. The results showed that T4 stage, PSA levels higher than $20 \mathrm{ng} / \mathrm{mL}$, and distant metastasis were not associated with OS in the widowed group. To sum up, surgery, T-stage, PSA levels higher than $20 \mathrm{ng} / \mathrm{mL}$, and distant metastasis might be confounding factors associated with OS in
Chinese patients with $\mathrm{PCa}$ (Table 4).

The smooth function and threshold effect analysis was performed to further validate the role of PSA levels on OS in Chinese patients with $\mathrm{PCa}$ between the nonwidowed group and the widowed group. The smoothed plots indicated that nonlinear relationships between the PSA level and OS in the widowed group and nonwidowed group, respectively. The risk of poor OS was increased rapidly with the PSA level up to the turning point 15.6 and $45.4 \mathrm{ng} / \mathrm{mL}$ in the nonwidowed group ( $\mathrm{HR}=1.089 ; 95 \% \mathrm{CI}: 1.064$ $1.115 ; \mathrm{P}<0.0001)$ and widowed group $(\mathrm{HR}=1.056 ; 95 \% \mathrm{CI}$ : $1.028-1.084 ; \mathrm{P}<0.001)$, respectively. However, the increased 
Table 2 Univariate and multivariate analysis on the overall survival of Chinese prostate cancer patients

\begin{tabular}{|c|c|c|}
\hline Variables & Univariate & Multivariate \\
\hline Married & 1 & 1 \\
\hline Married & $1.317(0.967,1.794) ; 0.08056$ & $1.061(0.772,1.457) ; 0.71543$ \\
\hline Divorced & $1.395(0.918,2.121) ; 0.11872$ & $1.398(0.918,2.127) ; 0.11804$ \\
\hline \multicolumn{3}{|c|}{ PSA categories } \\
\hline$<4$ & 1 & 1 \\
\hline$\geq 4,<10$ & $0.817(0.568,1.176) ; 0.27788$ & $0.770(0.534,1.111) ; 0.16252$ \\
\hline$\geq 10,<20$ & 1.500 (1.028, 2.187); 0.03526 & $1.313(0.897,1.921) ; 0.16141$ \\
\hline No & 1 & 1 \\
\hline Yes & $0.400(0.327,0.488) ;<0.00001$ & $0.462(0.368,0.580) ;<0.00001$ \\
\hline \multicolumn{3}{|l|}{$\mathrm{T}$} \\
\hline $\mathrm{T} 1$ & 1 & 1 \\
\hline $\mathrm{T} 2$ & 0.815 (0.686, 0.968); 0.01990 & $1.079(0.893,1.303) ; 0.43245$ \\
\hline T3 & 0.680 (0.482, 0.959$) ; 0.02776$ & $0.895(0.614,1.304) ; 0.56217$ \\
\hline $\mathrm{T} 4$ & $5.094(3.424,7.577) ;<0.00001$ & 2.480 (1.590, 3.869); 0.00006 \\
\hline \multicolumn{3}{|l|}{$\mathrm{N}$} \\
\hline
\end{tabular}

rate of risk of poor OS was decreased when the PSA level was higher than the turning point 15.6 in the nonwidowed group ( $\mathrm{HR}=1.013 ; 95 \% \mathrm{CI}: 1.005-1.021 ; \mathrm{P}<0.0001)$. However, there was no significant difference between poor OS and PSA levels in the widowed group (HR $=0.995 ; 95 \%$ CI: 0.958-1.034; $\mathrm{P}=0.8037)$ when the PSA level was higher than $45.4 \mathrm{ng} / \mathrm{mL}$ (Figure 2 and Table 5).

\section{Discussion}

Evidence has long been accumulating about the positive association between better health and being married for a number of reason $(19,20)$. Marriage, as an important type of social support, plays an important role in mental and physical health and mortality. Without social interaction and emotional support, widowed patients are more likely to receive less preventive healthcare and less aggressive treatments $(21,22)$. Thus, widowed patients are more likely to diagnosed at a later stage of the disease and receive less intensive therapies. What's more, being widowed has a greater impact on male cancer patients than female patients. Thus, being widowed might have a greater impact on $\mathrm{PCa}$ patients.

The results of this study demonstrate that widowed status is a negative consequence for Chinese PCa patients, which indicated that marital status has a favorable outcome 
Table 3 The characteristics of widowed patients and nonwidowed patients

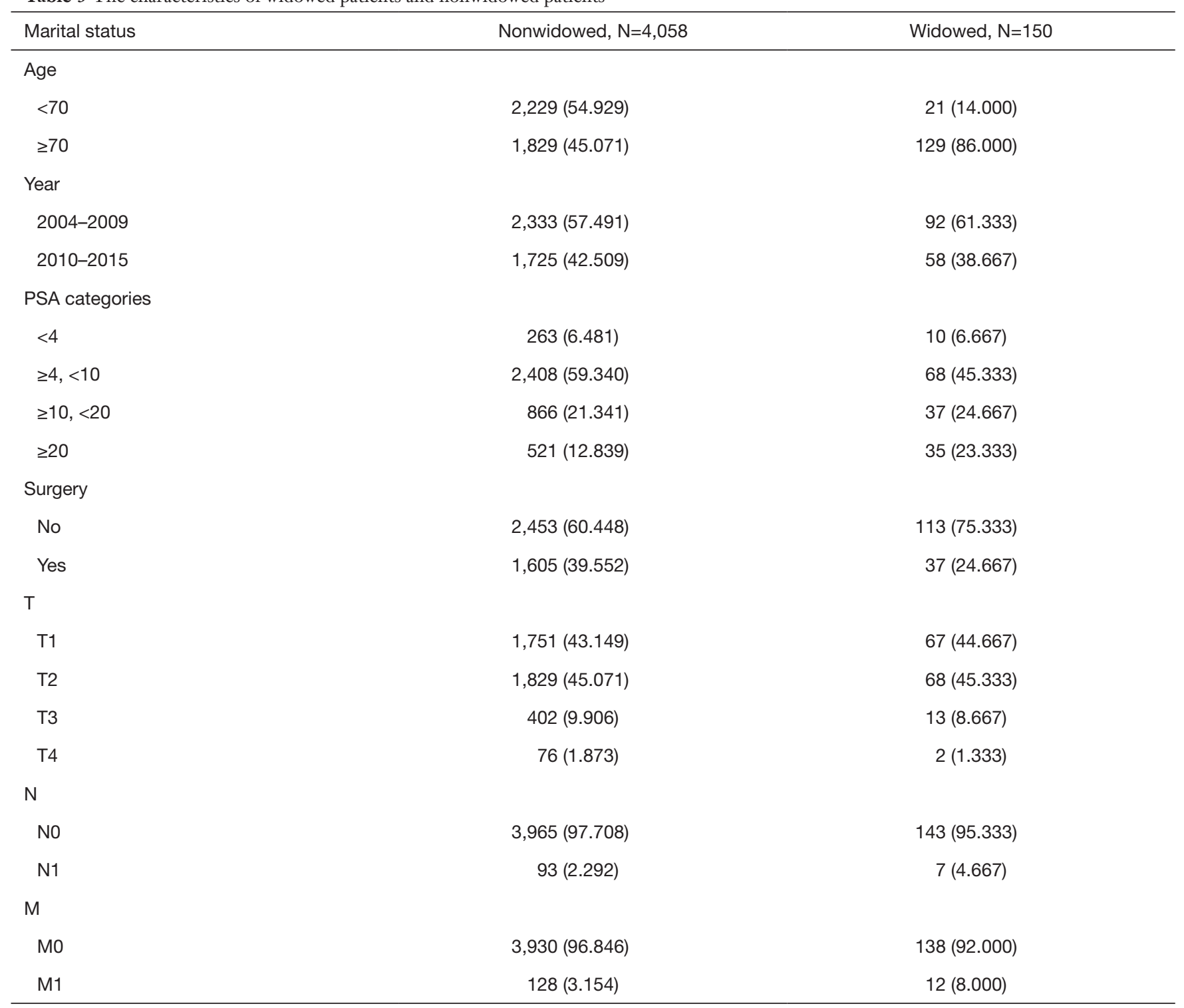

for patients. Previous studies $(9-11,23,24)$ also indicated that marital status was associated with a favorable outcome in various malignancies. However, in terms of $\mathrm{PCa}$, only two studies reported the same conclusions as this study. To the best of our knowledge, it is the first study to report the influence of marital status on OS in Chinese PCa patients.

In this study, marital status, PSA category, surgery status, $\mathrm{T}$ stage, and $\mathrm{M}$ stage were independent risk factors of OS. The widowed group had approximately a 2 -fold higher risk of poor OS than the married group. The survival outcomes of the single and divorced groups were comparable to the married group. This is in accordance with a previous study.
Liu et al. (25) reported that widowed men were more likely to die because of $\mathrm{PCa}$, with a 1.427 -fold higher risk of death than married men. The reasons why being married benefits PCa patients can be explained in the following paragraphs. First, the widowed PCa patients had the highest proportion of elderly patients, more patients with PSA higher than 20 $\mathrm{ng} / \mathrm{mL}$, the lowest proportion receiving surgery, and the highest proportion of metastasis. Second, surgery, T stage, and PSA level higher than $20 \mathrm{ng} / \mathrm{mL}$ might be confounding factors associated with OS in Chinese patients with $\mathrm{PCa}$. Compared with nonwidowed patients, widowed patients had a lower proportion of surgical treatment, which may be 


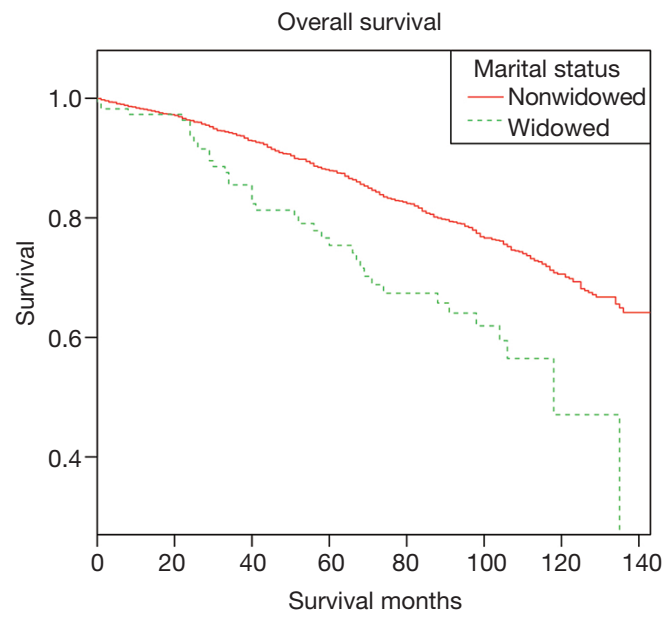

Figure 1 Overall survival of Chinese prostate cancer patients stratified by marital status. partly related to the poor OS. Third, the widowed group cannot benefit from well-balanced lifestyles and social interactions, which results in a poor prognosis.

In terms of the PSA category, we have demonstrated that PSA level higher than $20 \mathrm{ng} / \mathrm{mL}$ was associated with poor OS in Chinese PCa patients. In order to further validate the relationship between PSA level and marital status, a subgroup analysis was then performed to determine the role of PSA level in the widowed group and the nonwidowed group, respectively. The results indicated that PSA level higher than $20 \mathrm{ng} / \mathrm{mL}$ was not associated with a poor OS in the widowed group. However, there was a significant difference associated with PSA level higher than $20 \mathrm{ng} / \mathrm{mL}$ and poor OS in the nonwidowed group. The two-piecewise linear regression model was applied to examine the threshold effect of the PSA level on OS

Table 4 Multivariate analysis on overall survival of Chinese patients stratified by marital status

\begin{tabular}{|c|c|c|}
\hline Variable & \multicolumn{2}{|c|}{ Multivariate } \\
\hline \multicolumn{3}{|c|}{ PSA categories } \\
\hline$<4$ & 1 & 1 \\
\hline$\geq 4,<10$ & $0.784(0.534,1.151) ; 0.21481$ & $0.509(0.143,1.812) ; 0.29698$ \\
\hline$\geq 20$ & 2.179 (1.451, 3.272); 0.00018 & 1.639 (0.441, 6.091); 0.46057 \\
\hline \multicolumn{3}{|l|}{ Surgery } \\
\hline No & 1 & 1 \\
\hline Yes & $0.433(0.341,0.548) ;<0.00001$ & 0.667 (0.295, 1.504); 0.32860 \\
\hline \multicolumn{3}{|l|}{$\mathrm{T}$} \\
\hline $\mathrm{T} 2$ & $1.163(0.954,1.416) ; 0.13440$ & $0.535(0.275,1.039) ; 0.06473$ \\
\hline T3 & $0.966(0.652,1.431) ; 0.86326$ & $0.554(0.144,2.133) ; 0.39084$ \\
\hline $\mathrm{T} 4$ & 2.648 (1.683, 4.167); 0.00003 & $1.381(0.122,15.572) ; 0.79397$ \\
\hline \multicolumn{3}{|l|}{$\mathrm{N}$} \\
\hline No & 1 & 1 \\
\hline N1 & $1.138(0.710,1.822) ; 0.59124$ & 1.343 (0.361, 4.994); 0.66006 \\
\hline \multicolumn{3}{|l|}{ M } \\
\hline Mo & 1 & 1 \\
\hline
\end{tabular}




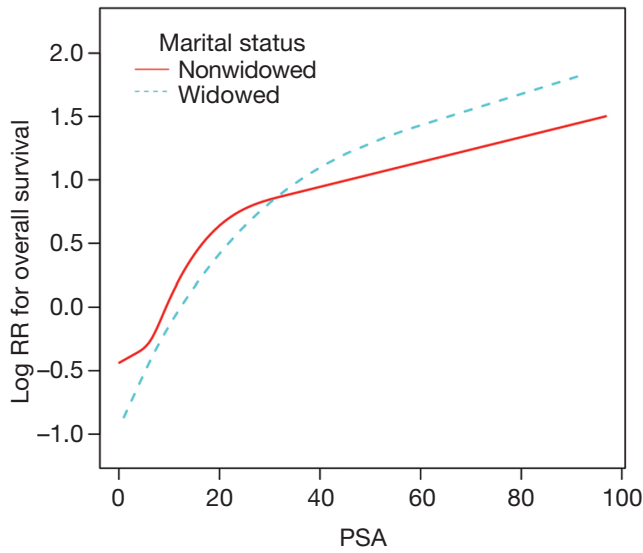

Figure 2 The relationship between PSA level and overall survival stratified by marital status. PSA, prostate-specific antigen.

Table 5 Threshold effect analysis of on using piecewise linear regression

\begin{tabular}{lcc}
\hline Marital status & Nonwidowed & Widowed \\
\hline $\begin{array}{l}\text { Inflection point (IP) of } \\
\text { PSA level }(\mathrm{ng} / \mathrm{mL})\end{array}$ & 15.6 & 45.4 \\
Lower than IP & $1.089(1.064,1.115) ;$ & $1.056(1.028,1.084) ;$ \\
& $<0.0001$ & $<0.0001$ \\
Higher than IP & $1.013(1.005,1.021) ;$ & $0.995(0.958,1.034) ;$ \\
& 0.0008 & 0.8037 \\
\hline
\end{tabular}

between the widowed group and the nonwidowed group by using a smoothing function. The threshold effect analysis demonstrated that the turning points of the PSA level were 15.6 and $45.4 \mathrm{ng} / \mathrm{mL}$ in the nonwidowed group and the widowed group, respectively. These results indicated that the risk of poor OS increased sharply with the PSA level up to 15.6 and $45.4 \mathrm{ng} / \mathrm{mL}$ in the nonwidowed group and the widowed group, respectively. It is the first study to report the relationship between the turning points of PSA level and marital status. Further studies are needed to validate these results.

Although this study is the first to explore the survival disparity between widowed and nonwidowed groups in Chinese PCa patients, the retrospective design and small sample should not be ignored. In this study, we have tried our best to analyze the differences in characteristics, demographics, and survival outcomes in Chinese $\mathrm{PCa}$ patients. This study also had some limitations. In the first place, more specific data that might be associated with the prognosis of $\mathrm{PCa}$, such as social status; history of smoking, drinking, or hypertension; and education cannot be acquired from the SEER database. Secondly, the timevarying marital status cannot be acquired from the SEER database. Therefore, marital status can only be analyzed as a baseline variation. Third, the Gleason score was an important risk factor associated with survival outcomes of PCa. However, a large portion of Gleason score data was missing in this study. Therefore, the Gleason score cannot be analyzed in this study.

\section{Conclusions}

In conclusion, this study demonstrated that widowed status greatly affects the OS of Chinese PCa patients. Taken together, this study highlights the importance of psychological intervention, especially for those who are widowed Chinese PCa patients. Timely psychological intervention for widowed Chinese PCa patients might improve the survival outcomes of PCa.

\section{Acknowledgments}

Funding: None.

\section{Footnote}

Conflicts of Interest: All authors have completed the ICMJE uniform disclosure form (available at http://dx.doi. org/10.21037/tcr.2019.11.48). The authors have no conflicts of interest to declare.

Ethical Statement: The authors are accountable for all aspects of the work in ensuring that questions related to the accuracy or integrity of any part of the work are appropriately investigated and resolved. All information from the SEER database has been deidentified. Informed consent is not required for use of SEER data.

Open Access Statement: This is an Open Access article distributed in accordance with the Creative Commons Attribution-NonCommercial-NoDerivs 4.0 International License (CC BY-NC-ND 4.0), which permits the noncommercial replication and distribution of the article with the strict proviso that no changes or edits are made and the original work is properly cited (including links to both the formal publication through the relevant DOI and the license). See: https://creativecommons.org/licenses/by-ncnd $/ 4.0 /$. 


\section{References}

1. Juanrivera MC, Martínezferrer M. Integrin Inhibitors in Prostate Cancer. Cancers 2018;10:44.

2. Xu N, Wu YP, Ke ZB, et al. Identification of key DNA methylation-driven genes in prostate adenocarcinoma: an integrative analysis of TCGA methylation data. J Transl Med 2019;17:311.

3. Wei Y, Liu L, Li X, et al. Current Treatment for Low-Risk Prostate Cancer in China: A National Network Survey. J Cancer 2019;10:1496-502.

4. Feng RM, Zong YN, Cao SM, et al. Current cancer situation in China: good or bad news from the 2018 Global Cancer Statistics? Cancer Commun (Lond) 2019;39:22.

5. Ye DW, Zhu Y. Prostate cancer and prostatic diseases Best of China, 2018. Prostate Cancer Prostatic Dis 2019;22:1-2.

6. Wu YP, Li XD, Ke ZB, et al. Risk factors for infectious complications following transrectal ultrasound-guided prostate biopsy. Infect Drug Resist 2018;11:1491-7.

7. $\mathrm{Xu} \mathrm{N}, \mathrm{Wu}$ YP, Yin HB, et al. Molecular network-based identification of competing endogenous RNAs and mRNA signatures that predict survival in prostate cancer. J Transl Med 2018;16:274.

8. Trudel-Fitzgerald C, Poole EM, Sood AK, et al. Social integration, marital status, and ovarian cancer risk: A 20-year prospective cohort study. Psychosom Med 2019;81:833-40.

9. Liu YL, Wang DW, Yang ZC, et al. Marital status is an independent prognostic factor in inflammatory breast cancer patients: an analysis of the surveillance, epidemiology, and end results database. Breast Cancer Res Treat 2019;178:379-88.

10. Zhai Z, Zhang F, Zheng Y, et al. Effects of marital status on breast cancer survival by age, race, and hormone receptor status: A population-based Study. Cancer Med 2019;8:4906-17.

11. Mao W, Zhang Z, Huang X, et al. Marital Status and Survival in Patients with Penile Cancer. J Cancer 2019;10:2661-9.

12. Huynh-Le MP, Klapheke A, Cress R, et al. Impact of marital status on receipt of brachytherapy and survival outcomes in locally advanced cervical cancer. Brachytherapy 2019;18:612-9.

13. Yang Y, Yuan G, Zhan C, et al. Benefits of surgery in the multimodality treatment of stage IIB-IIIC small cell lung cancer. J Cancer 2019;10:5404-12.

14. Chen B, Liu B, Wu C, et al. Prognostic factors among single primary gliosarcoma cases: A study using
Surveillance, Epidemiology, and End Results data from 1973-2013. Cancer Med 2019;8:6233-42.

15. Shen BJ, Xu Y, Eisenberg S. Psychosocial and Physiological Predictors of Mortality in Patients of Heart Failure: Independent Effects of Marital Status and C-Reactive Protein. Int J Behav Med 2017;24:83-91.

16. Beynon RA, Lang S, Schimansky S, et al. Tobacco smoking and alcohol drinking at diagnosis of head and neck cancer and all-cause mortality: Results from head and neck 5000, a prospective observational cohort of people with head and neck cancer. Int J Cancer 2018;143:1114-27.

17. Wu SG, Lin QJ, Li FY, et al. Widowed status increases the risk of death in vulvar cancer. Future Oncol 2018;14:2589-98.

18. Yu X, Cao L, Yu X. Elevated cord serum manganese level is associated with a neonatal high ponderal index. Environ Res 2013;121:79-83.

19. Springer KW, Lee C, Carr D. Spousal Breadwinning Across 30 Years of Marriage and Husbands' Health: A Gendered Life Course Stress Approach. J Aging Health 2019;31:37-66.

20. Umberson D, Donnelly R, Pollitt AM. Marriage, Social Control, and Health Behavior: A Dyadic Analysis of Same-sex and Different-sex Couples. J Health Soc Behav 2018;59:429-46.

21. Bennett-Britton I, Teyhan A, Macleod J, et al. Changes in marital quality over 6 years and its association with cardiovascular disease risk factors in men: findings from the ALSPAC prospective cohort study. J Epidemiol Community Health 2017;71:1094-100.

22. Saito T, Murata C, Aida J, et al. Cohort study on living arrangements of older men and women and risk for basic activities of daily living disability: findings from the AGES project. BMC Geriatr 2017;17:183.

23. Gao Z, Ren F, Song H, et al. Marital Status and Survival of Patients with Chondrosarcoma: A Population-Based Analysis. Med Sci Monit 2018;24:6638-48.

24. Li Y, Zhu MX, Qi SH. Marital status and survival in patients with renal cell carcinoma. Medicine (Baltimore) 2018;97:e0385.

25. Liu Y, Xia Q, Xia J, et al. The impact of marriage on the overall survival of prostate cancer patients: A Surveillance, Epidemiology, and End Results (SEER) analysis. Can Urol Assoc J 2019;13:E135-9.

Cite this article as: Huang SH, Li YN, Li JW, Guo YH, Su XF. Widowed status predicts poor overall survival of Chinese patients with prostate cancer. Transl Cancer Res 2020;9(2):595602. doi: $10.21037 /$ tcr.2019.11.48 